\title{
Small and Medium-Sized Enterprises (SMEs): Towards a New Paradigm
}

\author{
K. C. Koutsopoulos \\ Department of Geography, National Technical University Athens, Greece \\ 14 Kekropos Str., Drafi, Pikermi, 19009, Greece \\ E-mail: koutsop@survey.ntua.gr
}

This paper has been the result of the author's participation, as a EUROGEO partner, in the Green and Stable Bringing Sustainability and Environmental Action Together for Better Future (BALANCE) project.

\begin{abstract}
Assessing Small and Medium-sized Enterprises (SMEs) only in terms of economic indicators cannot be acceptable anymore. It is suggested that for an appropriate way to deal with SMEs there is a need for a new paradigm based on an integrated-holistic approach both in terms of the way they operate and of how they are managed. This paper presents the conceptualization of this new paradigm, supported by five principals substantiating it, as well as by the evolution of SMEs through time. In addition, the new paradigm in addressing any SME demands that a set of attributes should be taken into consideration that are related to: the advantages it exhibits; the enterprising environment within which it operates; and the greening aspects it applies. These three aspects represent different manifestations of "a whole", the dialectic entity of an SME. The proposed paradigm clarifies that in order to achieve an effective and efficient approach to SMEs, the nature of all the factors involved in determining their successful operation have to be fully understood and taking into consideration.
\end{abstract}

Keywords: SMEs Paradigm, Integration, Holistic Approach, SMEs Attributes.

DOI: $10.7176 / \mathrm{EJBM} / 13-13-03$

Publication date:July $31^{\text {st }} 2021$

\section{Introduction}

In the last few years, important changes have taken place in the way we view SMEs, resulting in a new approach in the way they operate and are managed. Basically, changes in the perception operation and managment of SMEs provided by scientific knowledge (Hamidatum and Sabariah, 2020; National SME Development Council, 2012; Selamat et al., 2011) and practicing experience, clearly indicate that a new approach towards EMEs is required. Indeed, for an effective and efficient use of SMEs to facilitate economic activities and consequently development, their nature and all aspects related to them have to be fully understood, because in turn they determine how they operate and managed in real economic conditions.

The position presented in this paper is simple in its explanation, but radical when is considered in terms of the existing beliefs and practices in the community concerned with SMEs. Today's policy makers, industrialists, SME owners, as well as academicians and researchers consider them in a one-dimensional (economic) manner. It is suggested that due to a paradigm shift that has taken place in the way SMEs are operating, a new multidimensional approach in considering their entrepreneurship is required. Basically, these changes, expressing the new EMSs paradigm, must be applied in order to have successful administrative, economic and development results. The goal of this paper is to substantiate that paradigm shift and its characteristics that certainly have led in enhancing their role and importance.

\section{SMES Paradigm Shifts}

The literature (Thapar, 2012) and experience show that the way individuals and society as a whole deal with and practice their economic activities are determined by what Furtado (1963) has called their "myths". Such "myths" are also determining SMEs, because they provide the necessary tools to satisfy their necessary functional conditions, systematic approaches and basic operational needs. These conditions and needs in turn are the result of the values that the SMEs concerned community accepts and they constitute the basis for the way the society and the economy face SMEs. It is essentially this system of values that justifies any approach to SMEs and provides the instrumental force in formulating their operation. From this perspective, it should be clear that in order to establish the right approach in considering nowadays SMEs entrepreneurship, it is necessary the reality of the SMEs "myths" to be confronted. As a result, the questions that need to be asked, which should reflect the social, economic, cultural etc., conditions, are: which are the "myths" and the "values" with which SMEs must be approached?

Categorically and without any unambiguity, this paper declares that at the center of the approach towards SMEs should be a holistic/integrated consideration. As a result, the focus of this paper is to examine the paradigm shifts showing the changes in the role and operation and management of SMEs through time leading to such approach. More specifically, it is suggested that there is a series of principles, in combination with SMEs 
time evolutions, which define their "myths" and substantiate the paradigm shifts that have been observed as well as represent the paper's contribution in explaining present day SMEs entrepreneurship.

\subsection{SMEs Principles}

Nowadays for an appropriate way to deal with SMEs there is an axiomatic need to accept that there have been changes both in terms of the way they are regarded and operate. This leads to the realization that present approaches to SMEs, are now absolute and we are in the period of a new paradigm. The justification of such a paradigm shift is based on the following principles: first, the determining factors in the observed changes in SMEs are the results of the changes in societal perceptions and beliefs; second, there are ample evidence that SMEs entrepreneurship is in the process of a new paradigm shift; third, the paradigm shifts have been catalytic in altering the way society and the economy is reacting to SME; fourth, the SMEs approach is by necessity holistic; and fifth, the new paradigm should be understood as representing the "confrontation" of SMEs with the societal and economic conditions imposed by the real world; These propositions clearly indicate that in order to understand the role, the value, the operation and the impact of SMEs, it is imperative that they should be examined.

\subsubsection{Principle 1}

This is the fundamental principle related to SMEs. It suggests that the determining force in the observed paradigm shifts in their role and in their enterprising approach are the results of changes in societal perceptions and beliefs. It is well documented that changes in societal values and goals through time, result in profound changes in all aspects of our lives (Koutsopoulos and Kotsanis, 2014), including the role SMEs are playing and operate. These changes represent what epistemologist Kuhn (1962), has termed paradigm shifts. It should be noted that changing paradigms are not rare or unexpected events in considering economic activities ( Jacobs and Laybourn-Langton, 2018).

\subsubsection{Principle 2}

This principle implies that the changes in SMEs role and entrepreneurship that have taken place, were determined by the way they were operating and managed within a given economic setting, during a specific time period, which in turn were the result of the existing societal and economic conditions. In other words, societal and economic conditions that exist at a certain time are the determining factors in shaping the nature and entrepreneurship of SMEs.

\subsubsection{Principle 3}

This principle is concerned with the changes in the way SMEs goals are achieved, since their operation by necessity is related to societal behavioral modifications. More specifically, societal behavioral modifications have changed from a simple one-dimensional approach focusing mainly on economic aspects of SMEs operation and management, to more sophisticated multi-dimensional approaches, where these intricate SMEs characteristics are the defining operational criteria as well as their contribution to economic activities.

\subsubsection{Principle 4}

The fourth principle is relatively easy to comprehend, but is in direct contrast with the prevailing practices. SMEs operation on a region, a country or an international economic environment, has to provide integrated services and products to be successful. Considering SMEs only in economic terms, ignoring factors such as stimulating growth, ensuring jobs, concerned with the well-being of citizens etc., is not acceptable anymore. In order for an integrated approach to be attained, however, there is a need for SMEs to consider at the same time internal and external factors in dialectic harmony and with respect to all dimensions of their operation. More specifically, a holistic approach is needed that leads to the integration of all SMEs factors and contributions, in order to overcome the fragmentation of their operating and managing approaches as well as of their social ramifications

\subsubsection{Principle 5}

The fifth principle suggests that the new SMEs paradigm, as a connection between SMEs and the economy, accommodating simultaneously enterprising and societal needs, should be understood as representing the confrontation of SMEs and all the economic and societal conditions of the real world. Because out of this gloss confrontation rises the enterprising world as it exists today, which is too broad to be handled by monodimensional (economic) approaches as well as by unstructured or non-integrated operations and management, with no regard for the holistic nature of that world. That is, the new SMEs paradigm transect economic conditions in achieving SMEs operation, management and profitability. It involves the overcoming of a series of enterprising challenges that greatly influence the operation and management of SMEs and help them to determine when and how to confront the real world and economy, by seeking out a holistic approach.

\subsection{SMEs evolution}

Throughout history, people have always been dependent on entrepreneurship. Of course, the entrepreneurship of each era might not have the same role and ignificance as today, but for their time it was certainly something for 
people to rely on it. People would always use the mode of entrepreneurship they had available to help make their lives easier and at the same time try to perfect it and bring it to the next level. This is how the concept of SMEs began and evolved. From an SMEs point of view three major enterprising changes have occurred, which in turn created the following three distinct SMEs eras.

2.2.1 Pre-industrial Era

The trade mark of this era is the luck of machines and tools to help perform tasks in a mass production mode, which in turn had established social attributes and forms of political and cultural organization that lasted up to the advent of the Industrial Revolution in the 1750s. Although these characteristics varied from region to region, depending on the culture of a given area or history of social and political life, they had a common impact on the nature and operation of the SMEs or their equivalent of this era. More specifically, the production and management activity of the pre-industrial era, gender, age, race, and ethnicity, exhibited two important characteristics that shaped the SMEs handicraft entrepreneurship of the era.

$>$ Family setting: Most of the production was done in family settings, so much so that no distinction existed between "family" and "work unit." These small, families/enterprises (the SMEs of the era), had to supply most of the goods and services that the mostly rural areas needed (making clothing, preserving food and treating illnesses as well as provide entertainment) (Volti, 2008). These unique and small enterprises exhibited a primitive administrative structure by providing a ready-made hierarchy reflecting age and gender, with fathers and older males exercising full authority over women and younger members of the family. In addition, all of them were assigned specified types of tasks. This arrangement, certainly not up to present standards, provided an efficient for that era work allocation and coordination by individual family members. As a result, these prodromes of the SMEs provided a relative efficient management structure and of course a good basis for their latter development.

$>$ Guilds: In the pre-industrial era and mainly in the urban areas the predominant form of work organization, which determined many aspects of working life were the guilds (groups of skilled workers performing specific tasks or producing particular products). The most interesting characteristic of the guilts was that they served also as charitable agencies and mutual aid associations providing assistance for members in difficulties, which gave them great influence as well as becoming the prodrome of SMEs Company Social Responsibility.

In sum, during the pre-industrial era the equivalent of SMEs were influential handicraft institutions characterized by luck of machinery and mass production, and with a primitive management structure, which was relative efficient for that time period (Figure 1).

2.2.2 The industrial Revolution Era

This era started at the end of the $18^{\text {th }}$ century and ended at the very end of the $20^{\text {th }}$ century. Its basic characteristic was the mechanization of industries, which resulted in industry to replace agriculture as the backbone of the economy. The industrial revolution era went through three (and for some four faces), as a result of new inventions, which provided new sources of power to support better entrepreneurship:

$>\quad$ The first Industrial Revolution in 1765: It is characterized by the very important invention of the steam engine, which with the help of the massive extraction of coal created a new type of energy propelling new forms of entrepreneurship.

The second Industrial Revolution in 1870: It is characterized by massive technological advancements that helped the emergence of new sources of power, such as: electricity, gas, and oil, which in turn change existing ways of production and management operations.

The Third Industrial Revolution 1969: It is characterized by the rise of innovations in electronics, telecommunications and computers, which provided high-level automation. In addition, two other industrial inventions: Programmable Logic Controllers (PLCs) and Robots, have given rise to a high-level automation. At this time the nuclear power also appeared, as energy source. All these created the foundation for a completely new world of entrepreneurship.

The Industrial Revolution marks a major turning point not only for big industries, but also for SMEs. Friedrich Engels (1902) wrote that the " industrial revolution, (is) a revolution which at the same time changed the whole of civil society" clearly illustrating that almost every aspect of daily life was influenced in some smaller or bigger way. Given that SMEs represented an important economic force, both their nature and their entrepreneurship evolved considerably. Unfortunately, at the same time SMEs retained an old fashion informal management structure, but mainly reverse their openness to different activities entrepreneurship ,to a pure economic one in response to big firms' competition (Figure 1)

2.2.3 The Internet and Artificial Intelligence Era

Some scientists include present day developments as the fourth face of the industrial revolution, but it is considered in this paper as a separate era. The internet and the Artificial Intelligence are leading towards the development of virtual reality worlds, which allows the "bending" of the laws of physics, as well as the development of alternative sources of power and entrepreneurship. As a result, worldwide economies in all 
levels (region, country and internationally) directly impact not only big enterprises, but mainly SMEs whose role and entrepreneurship follow a new paradigm that will be presented in detail next.

In sum, the SMEs "myths" (principles applied and enterprising changes) have resulted in SMEs paradigms shifts each one exhibiting unique characteristic related on one hand on the way SMEs were considered and on the other the entrepreneurship practiced at each era (Figure 1).

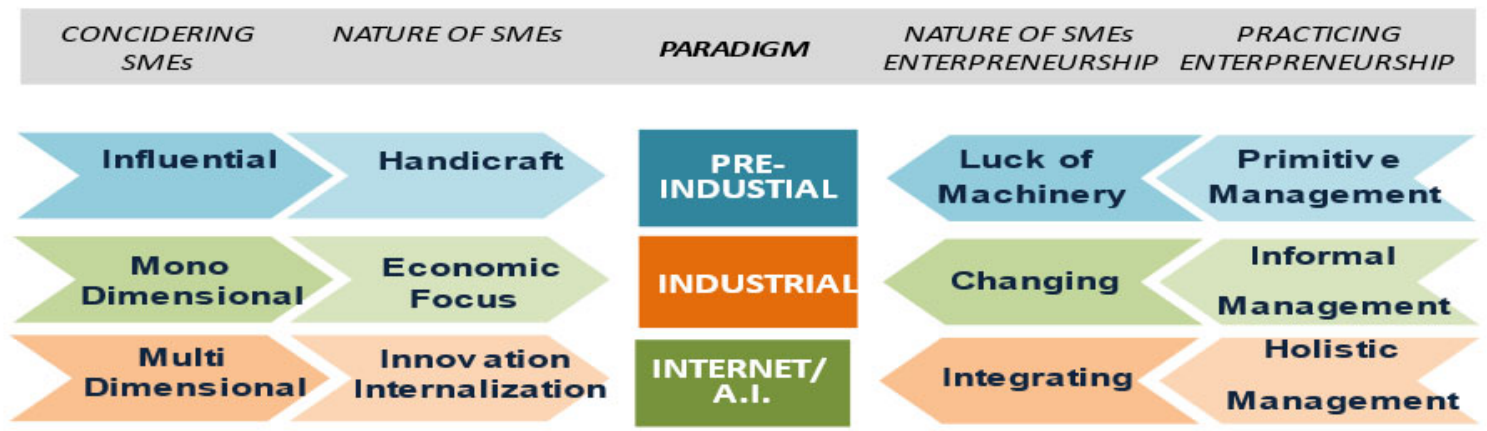

Figure 1. SMEs Paradigm Shifts

\section{The New SMEs Paradigm}

\subsection{SMEs Present Role and Entrepreneurship}

Jean-Claude Juncker, the former President of the European Commission had proclaimed that: "Jobs, growth and investment will only return to Europe if we create the right regulatory environment and promote a climate of entrepreneurship and job creation. We must not stifle innovation and competitiveness with too prescriptive and too detailed regulations, particularly when it comes to small and medium-sized enterprises (SMEs). SMEs are the backbone of our economy, creating more than $85 \%$ of new jobs in Europe and we have to free them from burdensome regulation."

Indeed, SMEs are playing today a significant role in the economic development, the social uplifting and the political stability of both developed and developing countries. SMEs can be established for any kind of business activities, in urban or rural area, are focused on diverse aspects of the economy and can be considered as the back bone of national economy (Peters and Waterman, 1982; Amini, 2004; Radam et al.,2008). For example: the annual report of the 2014/15 European Commission's on European SMEs (European commission, 2015) declared that these companies represent $99.8 \%$ of all enterprises in the non-financial business sector in the EU28, and they generate 58 cents in every Euro of value added. They also employ practically 90 million people representing $67 \%$ of the total EU employment. While on the other side of the globe, SMEs in India accounts for $45 \%$ of industrial output and 40\% of the total exports in India. They generate employment for 60 million people and create 1.3 million jobs every year. Given that a majority of India's population lives in villages and Tier-1/Tier 2 cities, the SME sector has also emerged as a key factor in urbanizing rural India (Featureline, 2020).

However, despite this central role of SMEs, there is substantial confusion over which characteristics should express them or more importantly how SMEs should be viewed and which policies are most appropriate and should be applied to help and support them. Understanding the nature and the approaches to SMEs are essential in framing such an important and necessary debate.

The literature has shown that in attempting to answer these widely acknowledging concerns, many provide evidence from individual countries and examine firm-specific characteristics like: life cycle (Yazdanfar and Öhman, 2015), internationalization (Majocchi et al., 2015), leverage (Asimakopoulos et al., 2009), entrepreneurial orientation (Soininen et al., 2012), trade credit (Martinez-Sola et al., 2014), capital growth (Fu et al., 2002), etc. Moreover, there are reports such as that of Gupta et.al. (2018) and Redmond and McGuinness, (2018) that focus on those SMEs factors known as "the failures of failure".

It is suggested that nowadays such approaches cannot be accepted. It is argued that there is a need for a different approach to SMEs, which must consider at the same time internal and external factors in dialectic harmony and with respect to all dimensions of their entrepreneurship. As a result, a holistic approach is needed that leads to the integration of all concerns, in order to overcome the fragmentation of knowledge and approaches related to SMEs operation and management as well as of their social ramifications.

In order to deal with issues related to such a holistic approach as well as the metrics required to address them. There is a need to answer the following questions: first, how appropriate is the present-day SMEs definitions; second, how the enterprising environment and internal and external challenges impact the SMEs role in the economy; and third how necessary are their greening attempts in order to meet their societal obligations and environmental operational needs. Each of these concerns provides complementary views of the SMEs landscape: the first question helps identify the pitfalls and limitations of the current SMEs definitions; the second 
indicates that SMEs exist within a specific enterprising environment, which determines their success or failure; while the third concern highlights the social importance of their greening process without constraining their growth and success. As a result, their examination is necessary.

\subsection{SMEs Holistic Approach}

\subsubsection{Definition of Small and Medium-sized Enterprises}

In examining the new SMEs paradigm, the first issue that needs to be considered is their definition. The term small and medium-sized enterprises (SMEs) is widely accepted and used by the European Union, the USA (without the clear definition of the EU) and many international organizations such as the World Bank, the United Nations and the World Trade Organization. In addition, the criteria for defining the size of a SME business differs from country to country. However, the definition and criteria used by the EU are representative of the mainstream approach in defining SMEs and are widely accepted as a guideline and a general «golden rule» that most countries strive to follow at least in the next few years. Basically, the European commission's definition of SME (2003/361/EC 2003) is the following: "The category of micro, small and medium-sized enterprises made up of enterprises which employ fewer than 250 persons and which have an annual turnover not exceeding EUR 50 million, and/or an annual balance sheet total not exceeding EUR 43 million." (European Commission, 2015)

The questions that immediately arise are: first, why is necessary to have a definition for SMEs? and second how appropriate are such definitions? The answer to the first question is simple, yet paramount, because the SME definition applies to all policies, programs and measures that most countries develop and apply to support SMEs, by providing the necessary guidelines in determining state aid.

In answering the second question relating to deciding whether or not a company is an SME is not as simple as one might think, as well as not as complete as the present-day condition require. In determining whether or not an enterprise is an SME, the enterprise's size (employees, turnover and balance sheet total amounts) are not the only factors that should be taken into account. In fact, an enterprise can be very small in these terms, but if it has access to significant additional resources (i.e., it is owned by, linked to or partnered with a larger enterprise), it might not qualify for SME status. In a similar manner, the necessity to: reduce $\mathrm{CO}_{2}$ emissions, transform the energy industry, move the production to a more environmental-friendly stage and many managing issues cannot be ignored when obtaining a complete picture of an SME in order to provide state aid.

\subsubsection{The role and Potential of the SME's}

In examining the new SMEs paradigm another issue that needs to be considered is their role and potential. The definition of an SME may vary from country to country (for example, the definition in Germany has a limit of 255 employees, while in Belgium it can be 100), but in all of them they are regarded as the key drivers of the national economy, representing the major contributor in sustaining modern-day economy. Small and mediumsized enterprises by creating the biggest portion of the gross value added, they play a key role in adding value in every sector of a country's economy. Most importantly, however, SMEs provide innovations spread throughout most regions to solve a series of national or regional challenges such as: climate change, resource efficiency and social cohesion. They are, therefore, fundamental in attaining the twin goals of a sustainable and a digital economy. Moreover, they are essential to: a region's or to a nation's competitiveness and prosperity, industrial ecosystems, economic and technological sovereignty, and resilience to external shocks.

In addition, SME enterprises are considered important, because they involve the: creation of jobs, reduction of unemployment, significant contribution to growth in GDP, achievement of sustainable growth, the ability of proper money flow across the economy, the establishment or the nursery from which large companies are created, direct contribution to significant aggregate savings and investment, development of appropriate technology, and in most cases charge lower rates to their clients by providing a quality business. Moreover, SMEs are a crucial element in the supplier network of large enterprises which are already on their way of becoming an Industry (Lutz, 2015).

Therefore, it should not be a surprise that SMEs greatly outnumber the number of large-scale companies operating in all countries in the world. Actually, the World Bank estimates that the SMEs represent about $90 \%$ of all businesses and contribute more than $50 \%$ to employment worldwide. But the important issue is that the factors contributing towards their growth are related to the internal and external enterprising environment they operate on, resulting in a differentiated importance and role across regions, countries and continents. For example, two companies having the exact defining characteristics (number of employees, turnover and balance sheets amounts), but operate in environments with: different funding opportunities, different presence of local and foreign investors, different availability of new technologies, various trade directories and trade portals will they be equally successful? In sum the enterprising environment represents an important source for potential growth of SMEs, as well as determining their success or failure.

\subsubsection{Greening of SMEs}

The third issue is related to the means required to achieve, within the new SMEs paradigm, a Greening approach. Small and medium-sized enterprises, all over the world, are confronted with rising pressures from society, the 
market and governments to meet environmental standards. At the same time, the demand for green products and services is rising, (the international green market is rapidly growing by $5 \%$ a year and is expected to triple by 2030). These two facts force a global shift towards a greener SMEs economy, which helps address environmental challenges, such as resource depletion and emissions. In addition, they bring economic benefits because many SMEs in order to improve their corporate image they try to cut their costs, while complying with standards related to green action plans for SMEs, in order to improve their compliance with environmental regulations.

Integrating the economy with the environment is of paramount importance and one of the top priorities in many countries. Moreover, the greatest opportunities for SMEs are in the concept of green growth, which is a means of reconciling economic growth with environmental sustainability (Samimi et al., 2011; Demaria, 2018; Robertson, 2019; Cohen, 2020). It is related to a sustainable development, which is seen as a way to achieve a green economy, by means of balancing the economic and environmental objectives or balancing short-term costs with long-term gains. In this way SMEs participate in: sustainable use of resources; increased share of renewable energy; preserving natural capital (air, water, land and wildlife); as well as reducing emissions and waste.

In sum, the greening of SMEs creates synergies between environmental protection and economic development, turning green investments into a driver of economic growth and competitiveness.

\subsection{Defining the New Paradigm}

Developed and developing countries' continuous economic development over the last decade has reached almost an impasse. Today they face multiple challenges related to stimulating growth, ensuring jobs and the well-being of their citizens. As a result, they are facing serious issues such as securing ecological sustainability, addressing climate change, and social cohesion, among others. There is a growing concern for resource scarcity, growing prices for materials, dependance on outside resources and mainly in attaining sustainable and digital economy, which are dependent on efficient and effective production processes.

These concerns suggest that nowadays the conditions, benefits and the impacts of SMEs on the economy and the society in general, can be assessed only through a holistic approach related to their integrated entrepreneurial processes. There is a need for a new paradigm, demanding important changes in the way we approach and consider SMEs. Indeed, scientific knowledge (Baron and Shane, 2007; Omerzel and Antoncic, 2008; Urban and Naidoo, 2012) clearly indicate that a new integrated approach to SMEs consideration, needs to be utilized to have successful results.

In determining such an approach, demands the building of a different paradigm in addressing an SME that should include a set of attributes related to: the advantages it exhibits; the enterprising environment within which it operates; and the greening aspects it applies. As a result, for an appropriate way to deal with SMEs there is a need for all factors related to SMEs entrepreneurship to be considered in dealing and assessing them. All of them contribute basic aspects related to the way they are regarded and assessed, and have an impact on the way SMEs are operating and managed. In essence, these three aspects represent different manifestations of "a whole", the dialectic entity of an SME.

In sum, all factors related to the SMEs existence should be considered in dealing and assessing them. For an appropriate way to deal with SMEs there is a need to take into consideration the important factors related to the way they are regarded, assessed, operating managed and generally dealt with. Thus, from a point in view related to their entrepreneurship existence and role, the following three major dimensions should be discerned (Figure 2).

\section{Approaching the SMES Paradigm}

It should be evident that there is a need for a transition to a new model of SMEs economic production and management that offer new opportunities for sustainable economic growth, which in turn requires the adoption of a new road to development and growth, based on alternative economic production models. Given, however, that SMEs are the principal actors in economic production as well as in building a circular and more resilient economy in most countries all over the world, there is a need to focus on them.

Indeed, SMEs, which by necessity represent the essential element of production and the principal way to address nowadays challenges, are forcing all governments to deal with them. Thus, focusing on SMEs is necessary, indisputable and in desperate need, but mostly it puts the traditional models of describing, and analyzing SMEs in a transitional situation. Assessing SMEs only in terms of economic indicators (staff headcount and either the turnover or balance sheet), cannot be acceptable anymore. It is suggested that to address SMEs, an integrated approach/paradigm is necessary, which has to simultaneously deal with: the degree an SME fulfils its multiple advantages (i.e., Informal Management, Flexibility etc.); the enterprising environment it conducts its business (i.e., Development Potential, Network and Supply Chains etc.); and the degree it approaches a climate-neutral state (i.e., eco-innovation, reduce $\mathrm{CO}^{2}$ emissions etc.), in an integrated manner respecting all these aspects. In other words, all factors related to the SMEs existence should be considered in dealing and assessing them. 


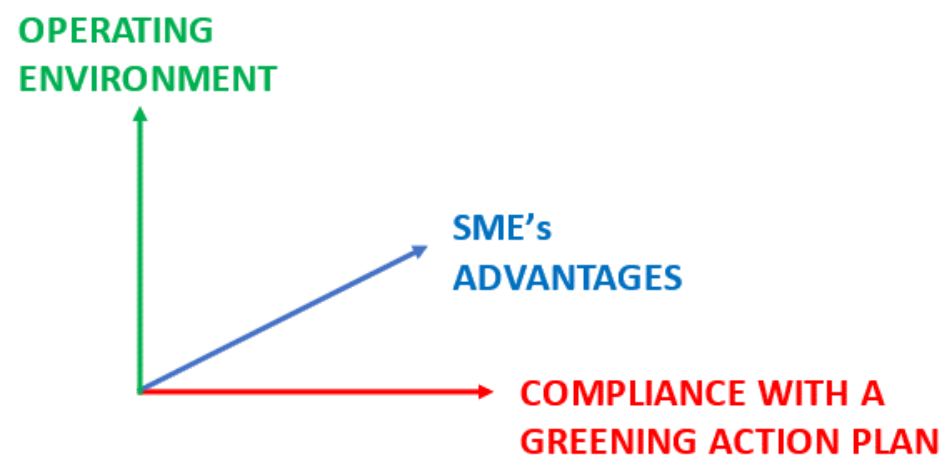

Figure 2. SMEs Determining Factors

The position substantiated in this paper is simple in its explanation, but radical when is considered in terms of the existing beliefs and practices in approaching SMEs. It is focused on the conceptualization of a new paradigm, which clarifies that in order to achieve an effective and efficient approach to SMEs, the nature of all the factors involved in determining their successful operation have to be fully understood, because in turn they determine the way the dual goals of circular and more resilient economy in any country can be implemented.

From the previous discussion an important need has surfaced, namely that important changes have to be made in the way we approach and consider SMEs. More specifically, it should be clear that in examining SMEs three dimensions play an important role, and a good understanding and a detail clarification of the elements of each of these components should be discerned as a prerequisite in approaching SMEs.

\subsection{The first dimension: SME Advantages}

The first dimension concerns the understanding of the many advantages that SMEs possess as enterprising entities (Bölükbaş and Güneri, 2017). As Anam (2019) has written, SMEs “... are able to do things that can be difficult for larger companies" and they should be taken into consideration. There are four important SME areas of advantages:

$>$ Operational Flexibility that allows then to encourage team spirit, to be closer to their customers and attain internal mobility.

$>$ Owners Direct control that allows an SME to have an individual decision maker that helps them to take immediate decisions, have an informal management style and easier communication within the enterprise.

$>$ Approach to Market, which allows them to better detect and take advantage of small market niches, easily change their market, easily interact with customers and be cost effective.

$>$ Capabilities for a series of enterprising actions such as to: innovate; adapt to changes; learn the market; have as locals a social role.

\subsection{The second dimension: Enterprising Environment and Challenges}

The second dimension is related to the various internal and external conditions and challenges that determine the entrepreneurial ability of an SME to operate (OESD, 2017; Kolympiris et al., 2007.; Adler and Shenbar, 1990 ; Lumpkin and Dess, 1996; Cogliser et al., 2008; Deepa et al., Manalel, J. 2016) and they should be taken into consideration The basic categories are:

$>$ Own Characteristics: These represent the most important factors that determine the successful operation or management of an SME and are connected with: the enterprise itself; the owner's characteristics and the qualification of its personnel (Radas and Božić, 2009).

$>$ Internal Challenges: There are several enterprising challenges that greatly influence the operation and/or management of SMEs. Among them are:

- Innovativeness, which depend on: External factors (Varis and Littunen, 2010); ICT Capabilities (Kaufmann and Tödtling, 2002); and Owners' perception of innovation (Koellinger, 2008; Marvel and Lumpkin, 2007; Robinson and Sexton, 1994).

- Internationalization, which in order to be achieved requires a set of difficult actions such as: Eliminating Risks; Acquiring Knowledge; Creating competitive advantages; Adapting to local frameworks; and Entrepreneurial orientation.

- Competitiveness: There is a need for the incorporation of new forms of SME development, such as design, eco-conception and corporate social responsibility.

- Planning: It represents a major challenge for SMEs in order to help them in: their day-to-day decision-making; evaluating their operation and progress; and allowing a constantly changing 
entrepreneurial environment.

- Maintaining profitability: this challenge has to be considered in order to: reduce costs; increase turnover; and increase productivity and efficiency.

- Increasing revenue: A number of challenging actions exist for an SME to increase revenue and maintain /sustain growth.

- Market commitment: It represents important challenges related to: the number of resources committed (marketing, personnel, organization etc.); and the degree of commitment (alternative use of resources and practices).

- Lack of technical knowledge. The lack of basic business skills and experience represent important constrain for SMEs. It is the reason that SMEs do not exist long enough to celebrate their fifth anniversary.

External Challenges: There is a big variety of external challenges related to the operation and management of SMEs that need to be taken into consideration by SMEs. A recent survey by Dutta (2020) in the UK listed as fundamental worries of the SMEs the following: Financial challenges $36 \%$; Technology risks 21\%; Regulatory compliance 17\%; Societal changes 13\%; and Supply and logistics $5 \%$.

$>$ Enterprising Constraints: In addition, however, there are many constraining factors related to their operation. Among the most important to be taken under consideration are: Access to capital; High bank interest rates (Welshet al.,1981); Poor Infrastructure and Facilities; Government regulation; and Environmental Entrepreneurship (greening processes and greening product and service offerings).

\subsection{The Third Dimension-Greening of SME's}

The third dimension is concerned with the quality of a good or service or a combination of both, as it relates to the environmental efficiency of an SME's production and its recycling processes. It is expressed by any Green Action Plan (GAP) instituted by regional, national or international entities, which set as a goal an SME to be climate-neutral, by turning environmental challenges into business opportunities and transition their economy into green. Such green action plans not only address immediate needs such as: support Circular Economy, reduce $\mathrm{CO}^{2}$ emissions, transform the energy industry, move the production to a more environmental-friendly stage and many more, but making a region or a country's economy more competitive and sustainable. But most importantly, turn SMEs environmental challenges into opportunities, reconcile economic growth with environmental sustainability and take advantage from the transition to a green economy.

The importance of any GAP concept lies in the recognition that the many SMEs activities have to be seen as different manifestations of "a whole", the entity of SMEs. Therefore, an integrated environmental approach towards SMEs is its basic principle and philosophy and should concentrate on the:

$>$ Objectives: any GAP should address a set of SMEs challenges in order to:

- Provide practical information, advice and support on how to improve their resource efficiency in a cost-effective manner.

- Support efficient technology transfer mechanisms for green technologies.

- Facilitate access to finance resource-related improvements and energy efficiency.

> Greening SMEs for More Competitiveness and Sustainability: GAP actions should be concerned with SMEs competitiveness and sustainability by:

- Providing SMEs with practical information, advice and support on how to improve their resource efficiency in a cost-effective manner.

- Supporting efficient technology transfer mechanisms for green technologies.

- Facilitating SMEs access in order to finance resource-related improvements and energy efficiency.

$>$ Support Green Entrepreneurship: GAP actions should be concerned with SMEs entrepreneurship issues, by providing incentives to:

- Promote all forms of eco-innovation business ideas, including non-technological eco-innovation.

- Facilitate business partnering, skills and knowledge for green entrepreneurship.

- Exploit the role of innovative clusters in support of eco-innovative SMEs.

$>$ Provide Opportunities of Greener Value Chains: GAP actions should be focused on fostering circular economy and long-term resource independence. As a result they should:

- Address systemic barriers to cross-sectoral and cross-national value chain collaboration and business creation and cooperation.

- Facilitate the creation of service business models.

- Re-use of materials, products and waste.

$>$ Facilitation of Market Access for Green SMEs: GAP actions should be concerned with SMEs market access and internationalization, in order to: 
- Promote a greener internal market

- Facilitate access to international markets for green entrepreneurs

- Facilitate the uptake of resource efficiency technology in partner countries through cooperation with national and international SMEs

Improving SME Resource Efficiency: GAP should be focused on:

- Providing information and advice to SMEs on how to improve their resource efficiency in a costeffective manner.

- Supporting green technology transfer.

- Facilitating access to finance for environmental improvements.

Treen value chain and circular economy: A GAP value chain can achieve:

- Enhancing cross-sectoral cooperation across the value chain.

- Cross-regional cooperation across the value chain.

- Share specialized knowledge.

\section{Conclusions}

The proposed conceptualization for a strategic consideration or a new paradigm governing the SMEs is based on a framework related to their principal entrepreneurial concerns, which are explained by a set of principals substantiating them as well as the evolution of SMEs through time, whose nature and objectives were identified and presented. It was shown that such a holistic and integrated entrepreneurship of SMEs is based on a threedimensional space consisting of the Advantages they exhibit, the Enterprising environment within which they operate, and the Aspects of GAP they apply. As a result, any EMSs consideration, appraisal or examination is necessary to take into consideration all these characteristics, which in turn they determine the way the dual goals of circular and more resilient economy in any region or country can be implemented. Finally, any SMEs consideration should be seen as a point defined in this three- dimensional space, because it:

$>$ Provides a very efficient and effective SMEs assessment tool.

$>$ Helps any administrative entity (from local to regional to international level) to recognize the context, in which SMEs operate.

$>$ Helps in understanding the integrated nature of SMEs.

$>$ Provides a comparison tool differentiating SMEs operation.

\section{References}

Adler, A., \& Shenbar, C. (1990). Adapting your technological base: The organizational challenge. Sloan Management Review. 25 (3), 25-37.

Amini, A. (2004). The distributional role of small business in development. International Journal of Social Economics. 31 (4), 370-383. Available at https://doi.org/10.1108/03068290410523395

Anam, A. (2019). The Advantages of SMEs. Bizfluent report. Available at https://bizfluent.com/info-8562480advantages-smes.html.

Asimakopoulos, I., Samitas, A. \& Papadogonas, T. (2009). Firm-specific and Economy Wide Determinants of Firm Profitability: Greek Evidence Using Panel Data. Managerial Finance. 11 (2), 930-939. Available at https://doi.org/10.1108/03074350910993818, (accessed 10 June 2021).

Baron, R.A. \& Shane, S.A. (2007), Entrepreneurship: A Process Perspective. (2nd Ed.). Mason, OH: Thomson South-Western,.

Bölükbaş, U. \& Güneri, A.F. (2017). A fuzzy multi-criteria decision approach for measuring technology competency performance of SMEs. Sigma Journal of Engineering and Natural Sciences. 8 (1), 31-40.

Cohen, S. (2020). Economic Growth and Environmental Sustainability. working paper, Earth Institute, Columbia University.

Cogliser, C.C., Brigham, K.A., \& Lumpkin, G.T. (2008). Entrepreneurial orientation (EO) research: A comprehensive review and analyses of theory, measurement, and data-analytic practices. Paper presented at the Entrepreneurship Research Conference in Babson College (accessed 10 June 2021).

Deepa, B. \& Manalel, J. (2016). Entrepreneurial orientation and firm performance: A critical examination. Journal of Business and Management. 18 (4), 21-28.

Demaria, F. (2018). Why economic growth is not compatible with environmental sustainability. Paper presented at the Ecologists Informed by Nature conference. Available at hhtp://theecology.org/2018/Feb/22/ whyeconomic-growth-not-compatible-environmental-sustainability (accessed 10 June 2021).

Dutta, D. (2020). Here are the biggest challenges SMEs in the UK are facing. Available at http://dataconomy.com/2020/02/here are the biggest challenges SMEs in the UK are facing, (accessed 10 June 2021).

European Commission. (2015). What is an SME? - Small and medium sized enterprises (SME).Web conference 
Enterprise and Industry (ec.europa.eu). Available at http://ec.europa.eu/eurostat/statistics explained/index.php/Statistics_on_small_and_mediumsized_enterprises (accessed 10 June 2021).

Engels, F. (1902). The Origin of the Family, Private Property and the State. Ernest Untermann (trans). Chicago: Charles H. Kerr \& Co.

European Commission. (2015), Annual Report on European SMEs 2014 / 2015. SMEs start hiring again. SME performance review 2014/2015.DOI: 10.2873/886211 (accessed 10 June 2021).

Featureline. (2020), "Statistics, Trends, Reports". SME Sector in India - Statistics, Trends, Reports EVOMA(accessed 10 June 2021).

Fu, T.W., Ke, M.C. \& Huang, Y.S. (2002). Capital Growth, Financing Source and Profitability of Small Businesses: Evidence from Taiwan Small Enterprises. Small Business Economics. 18, 257-267 https://doi.org/10.1023/A:1015291605542

Furtado, C. (1963). The Economic Growth of Brazil: A Survey from Colonial to Modern Times. Los Angeles: University of California Press.

Gupta, J., Gregoriou, A. \& Ebrahimi, T. (2018).Empirical Comparison of Hazard Models in predicting SMEs Failure. Quantitative Finance. 18 (3), 231-237.

Hamidatum, M. \& Sabariah, Y. (2020). SMEs' Perception on Supply Chain Risk: Does Size Matter? International Journal of Accounting, Finance and Business. 5 (27), 30-46.

Jacobs, M. \& Laybourn-Langton, L. (2018). Paradigm Shifts in Economic Theory and Policy. Intereconomics , $53,(3), 113-118$

Kaufmann, A. \& Tödtling, F. (2002). How effective is innovation support for SMEs? An analysis of the region of Upper Austria. Technovation,.22, (3), 147-159. https://doi.org/10.1016/S0166-4972(00)00081-X

Koellinger, P. (2008). Why are some entrepreneurs more innovative than others? Small Business Economics. 31, (1), 21-37.

Kolympiris, C., Klein, P. \& Kalaitzandonakes, N. (2007), The Entrepreneur's Choice of Location: Evidence from the Life Sciences. Presentation at American Agricultural Economics Association Annual Meeting, Portland, OR, July 29-August 1, 2007

Koutsopoulos, K. \& Kotsanis, Y. (2014). .School on Cloud: Towards a Paradigm Shift. Themes in Science and Technology Education 7 (1), 47-62.

Kuhn, T. (1962), The structure of scientific revolutions. Chicago: University of Chicago Press.

Lumpkin, G.T. \& Dess, G.G. (2001). Linking two dimensions of entrepreneurial orientation to firm performance: The moderating role of environment and industry life cycle. Journal of business venturing. 16 (5), 429-451.

Lutz, S. (2015). Revolution - industry 4.0: Are German manufacturing SMEs the first victims of this revolution? Journal of Industrial Engineering and Management. 8 (5), 1512-1532, DOI:10.3926/jiem.1470.

Majocchi, A. et al. (2017). Bifurcation bias and exporting: can foreign work experience be an answer? Insights from European family SMEs. Journal of World Business. 53 (2), 237-247.

Martinez-Sola, C., Garcia-Teruel, P.J. \& Martinez-Solano, P. (2014). Trade credit and SME Profitability. Small Business Economics. 42 (3), 561-577.

Marvel, M.R. \& Lumpkin, G.T. (2007). Technology entrepreneurs' human capital and its effects on innovation radicalness. Entrepreneurship Theory and Practice. 31 (6), 807-828.

National SME Development Council. (2012). Summary SME masterplan 2012-2020: catalyzing growth and income Available from, https://www.researchgate.net/publication/342735407_SMEs'_Perception_on_Supply_Chain_Risk_Does_Si ze_Matter (accessed 10, June 2021).

OECD. (2017), Enhancing the Contributions of SMES in a Global and Digitalized Economy. In Meeting of the OECD Council at Ministerial Level (pp. 1-24). Paris: OECD. Available from: https://www.oecd.org/mcm/documents/C-MIN-2017-8-EN.pdfKfW. (Accessed 10 June, 2021).

Omerzel, D.G. \& Antoncic, B. (2008). Critical entrepreneur knowledge dimensions for the SME performance. Industrial Management and Data Systems. 108 (9), 1182-1199.

Peters, T.J. \& Waterman, R. (1982). In Search of Excellence. New York: Harper \& Row.

Radam, A. Abu, B. L. \&Abdullah, C.M. (2008). Technical Efficiency of Small and Medium Enterprise in Malaysia: A Stochastic Frontier Production Model. International Journal of Economics and Management. 2 (2), 508-515

Radas, S. \& Božić, L. (2009).The antecedents of SME innovativeness in an emerging transition economy. Technovation 29 (6-7), 438-450.

Redmond, P. \& McGuinness, S. (2018.Assessing the Impact of the Minimum Wage in Ireland.. ifo DICE Report 4 (16).

Robertson S. (2019). Can economic growth be environmentally sustainable? Lending Works. Available at: https://www.lendingworks.co.uk/blog/economy/Can Economic Growth Be Environmentally Sustainable? | Economy News (lendingworks.co.uk). 
Robinson, P.B. \& Sexton, E.A. (1994). The effect of education and experience on self-employment success. Journal of Business Venturing. 9 (2), 141-156.

Selamat, N. H., Abdul-Razak, R. R., Gapor, S. A. \& Sanusi, Z. A. (2011). Survival through entrepreneurship: Determinants of successful micro-enterprises in Balik Pulau, Penang Island, Malaysia. British Journal of Arts and Social Sciences. 3 (1), 23-37.

Samimi, J. A., Ghaderi, S. \& Ahmadpour, M.(2011). Marginal intra-industry trade and adjustment costs: the case study of Iran's manufacturing industries. Advances in Environmental Biology. 5 (5), 961-966.

Soininen, M., Kaisu-Puumalainen, K. \& Kyläheiko, K. (2012). "Entrepreneurial Orientation: Growth and Profitability of Finnish Small and Medium-Sized Enterprises. International Journal of Production Economics. 140 (2), 614-622.

Thapar, R. (2012), "Society and Economic Activity". Romila Thapar (ed) Aśoka and the Decline of the Mauryas ,Oxford Scholarship Online, Oxford, UK. DOI: 10.1093/acprof: oso/9780198077244.001.0001.

Urban, B. \& Naidoo, R. (2012). Business sustainability: empirical evidence on SME operational skills in South Africa. Journal of Small Business and Enterprise Development. 19(1), 146-163.

Varis, M. \& Littunen, H. (2010). Types of innovation, sources of information and performance in entrepreneurial SMEs. European Journal of Innovation Management. 13 (2), 128-154.

Welsh, A. White, J. f. \& Dowell, P. (1981). A Small Business is not a Little Big Business.European Small Business Journal. 1 (1), 95-95.

Yazdanfar, D. \& Öhman, P. (2015). Debt financing and firm performance: an empirical study based on Swedish data. Journal of Risk Finance. 16 (1), 102-118. IN INDIA - STATISTICS, TRENDS, REPORT

Volti, R. (2008). An introduction to the sociology of work and occupations. Los Angeles: Pine Forge Press. 